\title{
Validation of the severity index by cardiac catheterization and Doppler echocardiography in patients with aortic sclerosis and stenosis
}

\author{
David M Shavelle*1, Nediljka Buljabasic ${ }^{1}$, Junichiro Takasu ${ }^{1}$, \\ Ashkan Babaie ${ }^{1}$, Joseph Rosales ${ }^{1}$, Matthew J Budoff ${ }^{1}$ and Kevin D O'Brien ${ }^{2}$
}

\author{
Address: ${ }^{1}$ Los Angeles BioMedical Research Institute at Harbor-UCLA Research, Division of Cardiology, Torrance, CA, USA and ${ }^{2}$ Division of \\ Cardiology, University of Washington, Seattle, WA, USA \\ Email: David M Shavelle* - dshavelle@hotmail.com; Nediljka Buljabasic - nbuljubasic@labiomed.org; Junichiro Takasu - ajtakasu@home.com; \\ Ashkan Babaie - ababaie@yahoo.com; Joseph Rosales - jrosales@hotmail.com; Matthew J Budoff - mbudoff@labiomed.org; \\ Kevin D O'Brien - cardiac@u.washington.edu \\ * Corresponding author
}

Published: 21 March 2006

Cardiovascular Ultrasound 2006, 4:12 doi:10.1 |86/1476-7|20-4-12
Received: 0I February 2006

Accepted: 21 March 2006

This article is available from: http://www.cardiovascularultrasound.com/content/4/I//2

(C) 2006 Shavelle et al; licensee BioMed Central Ltd.

This is an Open Access article distributed under the terms of the Creative Commons Attribution License (http://creativecommons.org/licenses/by/2.0), which permits unrestricted use, distribution, and reproduction in any medium, provided the original work is properly cited.

\begin{abstract}
The severity index is a new echocardiographic measure that is thought to be an accurate indicator of aortic leaflet pathology in patients with AS. However, it has not been validated against cardiac catheterization or Doppler echocardiographic measures of AS severity nor has it been applied to patients with aortic sclerosis. The purposes of this study were to compare the severity index to invasive hemodynamics and Doppler echocardiography across the spectrum of calcific aortic valve disease, including aortic sclerosis and AS. 48 patients with aortic sclerosis and AS undergoing echocardiography and cardiac catheterization comprised the study population. The aortic valve leaflets were assessed for mobility (scale I to 6) and calcification (scale I to 4) and the severity index was calculated as the sum of the mobility and calcification scores according to the methods of Bahler et al. The severity index increased with increasing severity of aortic valve disease; the severity indices for patients with aortic sclerosis, mild to moderate AS and severe AS were $3.38 \pm$ $1.06,6.45 \pm 2.16$ and $8.38 \pm 1.41$, respectively. The aortic jet velocity by echocardiography and the square root of the maximum aortic valve gradient by cardiac catheterization correlated well with the severity index $(r=0.84, p<0.000 I ; r=0.84, p<0.000 I$, respectively). These results confirm that the severity index correlates with hemodynamic severity of aortic valve disease and may prove to be a useful measure in patients with aortic sclerosis and AS.
\end{abstract}

\section{Background}

Aortic stenosis (AS) and aortic sclerosis are common findings in elderly patients, affecting $50 \%$ of those over the age of 84 years [1]. Echocardiography provides an accurate noninvasive assessment of disease severity and progression $[2,3]$. Studies have found that the presence of aortic valve calcium is associated with increased disease severity and predicts more rapid disease progression [4]. Bahler et. al. proposed that the severity index, a measure of both aortic valve leaflet calcium and mobility, was an accurate indicator of aortic leaflet pathology in patients with AS [5]. However, this new echocardiographic score has not been validated against cardiac catheterization measures of AS severity. Moreover, this index has not been 
validated against either cardiac catheterization or Doppler echocardiography in patients with aortic sclerosis. Therefore, the purposes of this study were to compare the severity index to invasive hemodynamics and Doppler echocardiography across the spectrum of calcific aortic valve disease, including aortic sclerosis and AS.

\section{Methods}

\section{A. Study population}

48 patients with aortic valve disease (aortic sclerosis and AS) identified by echocardiography with subsequent referral for invasive hemodynamic assessment of AS severity comprised the study population. All patients were referred for echocardiography by their treating physicians after a systolic murmur was detected. Patients underwent standard left and right heart catheterization for assessment of AS severity within one month of the echocardiogram. The institutional review board of Harbor-UCLA Research and Education Institute approved the study protocol. At the time of cardiac catheterization, information was obtained regarding the presence of traditional cardiovascular risk factors, including hypertension, family history of premature coronary artery disease, hyperlipidemia, smoking, and diabetes mellitus.

Patients were classified as having hypertension if they were receiving anti-hypertensive medications or had known but untreated hypertension (systolic blood pressure $>140 \mathrm{~mm} \mathrm{Hg}$ or diastolic blood pressure $>90 \mathrm{~mm}$ $\mathrm{Hg}$ ). Family history of coronary artery disease was defined as premature coronary artery disease (occurring in men age less than 45 years and women age less than 55 years) in a first-degree relative. Hyperlipidemia was defined as use of cholesterol lowering medication or, in the absence of cholesterol lowering medication use, as having a total serum cholesterol $>240 \mathrm{mg} / \mathrm{dL}$. Smoking was defined as the use of $>10$ cigarettes/day. Patients receiving insulin or oral hypoglycemic agents were classified as having diabetes mellitus.

\section{B. Cardiac catheterization}

Standard retrograde left and right heart catheterization was performed to evaluate AS severity. The left ventricle was entered by the retrograde approach. Left ventricular and aortic pressures were measured simultaneously using a 6 French pigtail catheter within the left ventricle, and a second 6 French pigtail catheter positioned in the ascending aorta. Computer assisted measurements of the peakto-peak, maximum and mean gradients were obtained. Cardiac output was measured by the Fick method. Aortic valve area was calculated using the Gorlin equation [6].

Aortic sclerosis was defined as the presence of aortic valve leaflet calcification or thickening (increased echogenicity) and no restriction to leaflet excursion by echocardiogra- phy and a maximum gradient by catheterization of less than $15 \mathrm{~mm} \mathrm{Hg}$. Mild AS was defined as a maximum gradient by catheterization of greater than $15 \mathrm{~mm} \mathrm{Hg}$ and less than $36 \mathrm{~mm} \mathrm{Hg}$. Moderate AS was defined as a maximum gradient by catheterization of greater than $36 \mathrm{~mm}$ $\mathrm{Hg}$ and less than $64 \mathrm{~mm} \mathrm{Hg}$. Severe AS was defined as a maximum gradient by catheterization of greater than 64 $\mathrm{mm} \mathrm{Hg}$. For the statistical analysis, patients with mild AS and moderate AS were included as one group. Patients could be grouped in similar categories using the aortic valve area by the Gorlin equation (data not shown); however, the aortic valve area was not calculated for patients with a maximum gradient by catheterization of less than $15 \mathrm{~mm} \mathrm{Hg}$.

\section{Echocardiography}

Doppler-echocardiography examinations were performed on a Hewlett-Packard 77020 AC echocardiographic scanner (Hewlett-Packard, Palo Alto, CA). The peak instantaneous transvalvular aortic jet velocity was determined by interrogating the aortic valve with continuous wave Doppler from multiple acoustic windows in order to obtain the highest jet velocity. Mean Doppler velocities were calculated by averaging the instantaneous Doppler gradients throughout the ejection period using an on-line quantification package. Three cardiac beats were averaged and the spectral display velocity curve was traced by hand. Anatomic measurements of the diameter of the left ventricular outflow tract were made from the two-dimensional parasternal long-axis view, parallel and adjacent to the aortic valve plane.

AS was defined as the presence of a peak instantaneous transaortic jet velocity of $\geq 2.0 \mathrm{~m} / \mathrm{sec}$ and restriction to valve leaflet opening in the presence of normal left ventricular systolic function. Patients with AS were further classified as mild AS (transaortic jet velocity 2.0 to $3.0 \mathrm{~m} /$ $\mathrm{sec}$ ), moderate AS (transaortic jet velocity 3.0 to $4.0 \mathrm{~m} /$ $\mathrm{sec}$ ) and severe AS (transaortic jet velocity $>4.0 \mathrm{~m} / \mathrm{sec}$ ) [2]. Aortic sclerosis was defined as the presence of aortic valve leaflet calcium or leaflet thickening and a peak instantaneous transaortic jet velocity of $<2.0 \mathrm{~m} / \mathrm{sec}$.

The aortic valve leaflets were assessed for mobility and calcification according to the methods described by Bahler et. al. [5]. The aortic valve leaflets were assessed in both the parasternal long- and short-axis views. Aortic leaflet calcification was graded according to the scale: $1=$ none, $2=\geq 1$ localized area of increased reflectivity but no areas of dense calcification, $3=$ markedly increased reflectivity (calcification) in one leaflet but equal to or less than grade 2 changes in other leaflets, $4=$ markedly increased reflectivity in 2 leaflets but equal to or less than grade 2 changes in the third leaflet, $5=$ moderately increased reflectivity in all leaflets and $6=$ severely increase reflectivity in all leaf- 
lets. Leaflet mobility was graded according to the scale: 1 = normal leaflet mobility, 2 = restriction of only 1 leaflet with normal mobility of the other leaflets or mild restriction of all leaflets, $3=$ marked restriction of 2 leaflets or moderate restriction of all leaflets, and $4=$ almost no mobility of any leaflet. The calcification and mobility scores were summed to yield the severity index.

\section{Statistical analyses}

Statistical analyses were performed using SAS v.6.12 (SAS Institute, Cary, NC) or GraphPad Prism, Version 3.02 (GraphPad Software, Inc., La Jolla, CA). Comparisons amongst the three groups (aortic sclerosis, mild to moderate AS and severe AS determined by cardiac catheterization) were done using one-way analysis of variance for continuous variables (age, maximum aortic valve gradient, transaortic jet velocity, severity index) and likelihood ratio chi-square for discrete variables (gender, hypertension, diabetes, hyperlipidemia, smoking, family history, aortic valve calcium, aortic valve mobility). These were overall tests to determine if any two groups differed from one another. Because cardiac catheterization gradients were not normally distributed, regression analysis with this variable was performed using square root-transformed values.

\section{Results}

\section{A. Patient characteristics}

For the 48 patients, the mean $( \pm \mathrm{SD})$ age was $56.1 \pm 9.6$ years and $32(67 \%)$ were male. The prevalence of cardiovascular risk factors was: hypertension 32 (67\%), smoking 19 (40\%), diabetes mellitus 17 (35\%), hyperlipidemia 20 $(42 \%)$, and family history of coronary artery disease 16 (33\%). Twenty-eight patients had aortic sclerosis, 12 had mild to moderate AS and 8 had severe AS.

\section{B. Cardiac catheterization}

For the entire group of patients, the maximum aortic valve gradient was $26 \pm 30 \mathrm{~mm} \mathrm{Hg}$. For patients with aortic sclerosis, mild to moderate AS and severe AS, the mean $( \pm \mathrm{SD})$ maximum aortic valve gradients were $7.0 \pm 2.8,30 \pm 16$ and $83 \pm 24 \mathrm{~mm} \mathrm{Hg}$, respectively (Figure 1A). The square root of the maximum aortic valve gradient by catheterization correlated well with the severity index $(\mathrm{r}=0.84, \mathrm{p}<$ 0.0001 , Figure 1B).

\section{Echocardiography}

For the entire group of patients, the mean $( \pm \mathrm{SD})$ transaortic jet velocity by echocardiography was $1.5 \pm 0.4 \mathrm{~m} / \mathrm{sec}$. For patients with aortic sclerosis, mild to moderate AS and severe AS, the mean $( \pm \mathrm{SD})$ transaortic jet velocities was $1.29 \pm 0.27,2.65 \pm 0.70$ and $4.54 \pm 0.60 \mathrm{~m} / \mathrm{sec}$, respectively. The severity index for the entire group of patients was $5.0 \pm 2.5$. The severity index increased with increasing severity of aortic valve disease and was significantly differ-
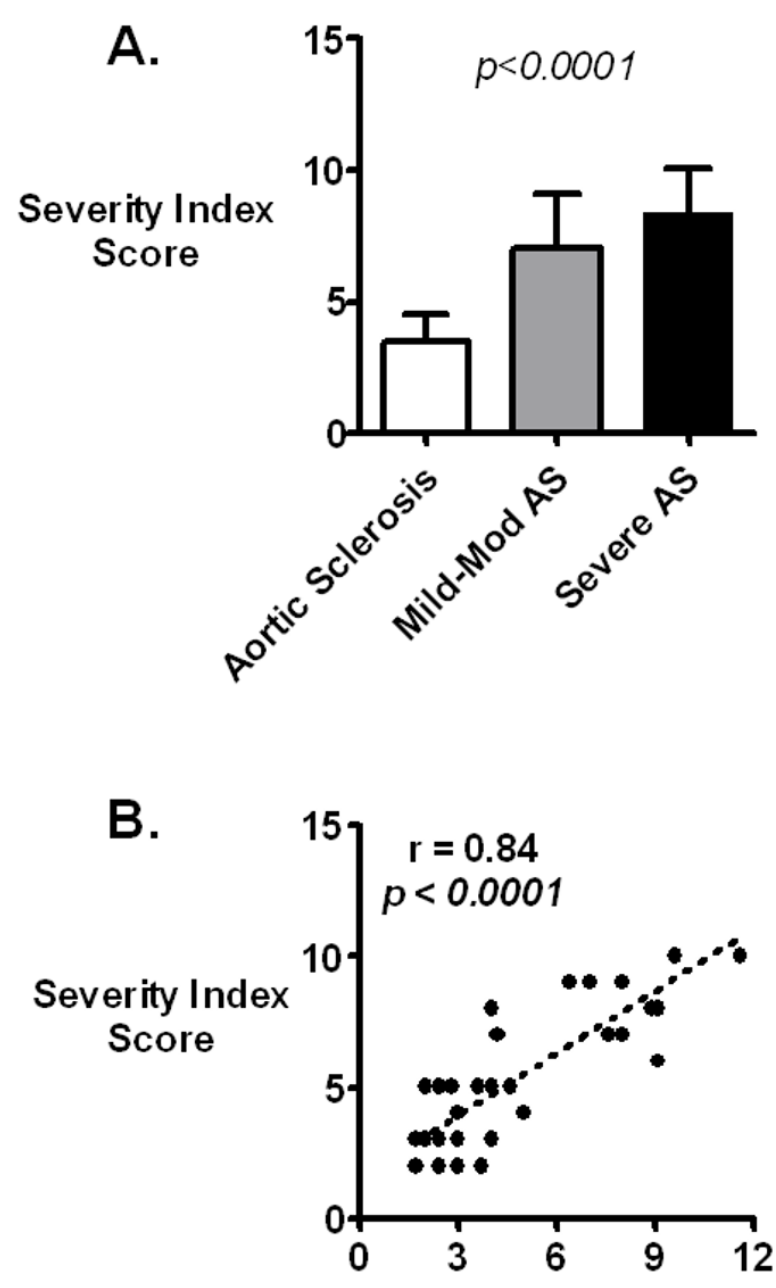

SqRt Valve Gradient

Figure I

Catheterization Gradient vs. Severity Index. A. Severity index as determined by cardiac catheterization for patients with aortic sclerosis (maximum gradient $<16$ $\mathrm{mmHg}$ ), mild to moderate AS (maximum gradient 16-64 $\mathrm{mmHg}$ ) and severe AS (maximum gradient $>64 \mathrm{mmHg}$ ). The severity index increased with increasing severity of aortic valve disease and was significantly different between the three groups $(p<0.0001$ by one-way analysis of variance [ANOVA]). B. Correlation of Catheterization Gradient with Severity Index. There was a strong correlation between square root-transformed maximum catheterization gradient and severity index $(r=0.84)$.

ent among each patient group; the severity indices for patients with aortic sclerosis, mild to moderate AS and severe AS were $3.38 \pm 1.06,6.45 \pm 2.16$ and $8.38 \pm 1.41$, respectively (Figure $2 \mathrm{~A}$ ). Aortic jet velocity correlated well with the severity index $(r=0.84, p<0.0001$, Figure $2 B)$. The severity index was significantly higher in patients with 

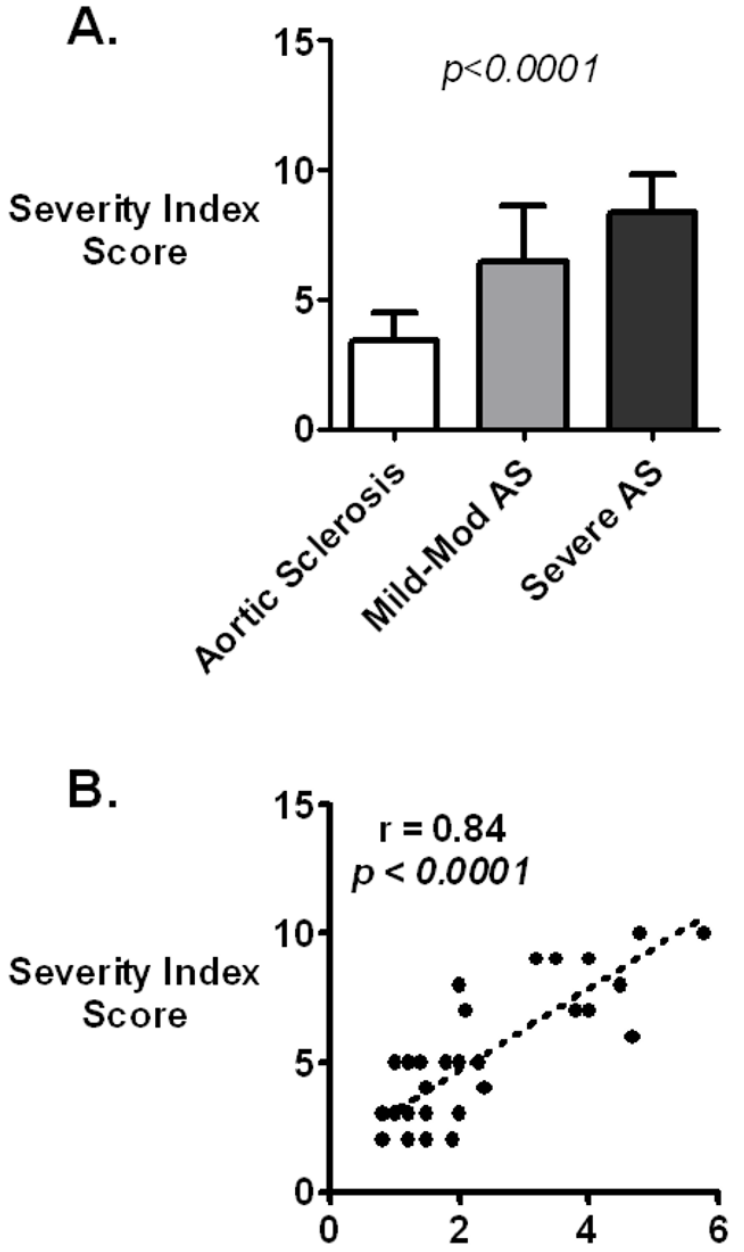

\section{Aortic Jet Velocity $(\mathrm{m} / \mathrm{sec})$}

\section{Figure 2}

Doppler Echocardiography vs. Severity Index. A. Severity index as determined by Doppler echocardiography for patients with aortic sclerosis (aortic jet velocity $<2.0 \mathrm{~m} /$ $\mathrm{sec}$ ), mild to moderate AS (aortic jet velocity $2.0-4.0 \mathrm{~m} / \mathrm{sec}$ ) and severe AS (aortic jet velocity $>4.0 \mathrm{~m} / \mathrm{sec}$ ). The severity index increased with increasing severity of aortic valve disease and was significantly different between the three groups $(p<0.000$ l by one-way [ANOVA]). B. Correlation of maximum Doppler aortic jet velocity with Severity Index. There was a strong correlation between aortic jet velocity and severity index $(r=0.84)$.

a high maximum aortic valve gradient ( $>16 \mathrm{~mm} \mathrm{Hg}$ ) compared to patients with a low maximum aortic valve gradient $(\leq 16 \mathrm{~mm} \mathrm{Hg}), 7.80 \pm 1.78$ and $3.63 \pm 1.35$, respectively (Figure 3 ).

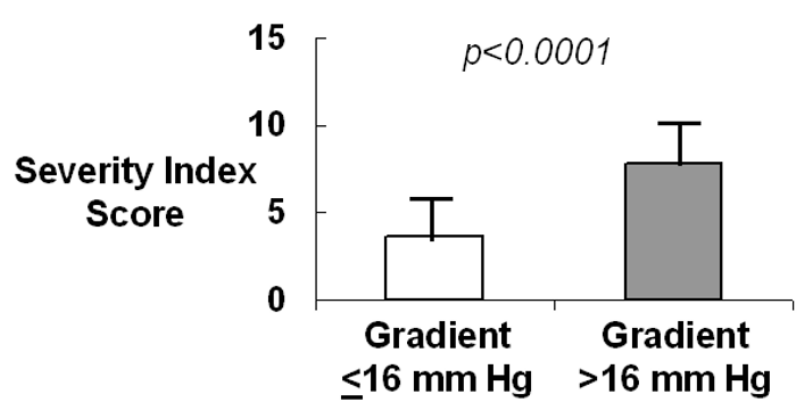

\begin{abstract}
Figure 3
Severity Index in Patients with a Low $(<16 \mathrm{~mm} \mathrm{Hg})$ and High ( $\geq 16$ mm Hg) Maximum Aortic Gradient. The severity index was significantly higher in patients with a high maximum aortic valve gradient $(>16 \mathrm{~mm} \mathrm{Hg})$ compared to patients with a low maximum aortic valve gradient $(\leq 16$ $\mathrm{mm} \mathrm{Hg}), 7.80 \pm 1.78$ and $3.63 \pm 1.35$, respectively $(\mathrm{p}<$ 0.000 I by one-way [ANOVA]).
\end{abstract}

\section{Discussion}

The initial study describing the importance of aortic valve calcium in patients with aortic valve disease was reported by Waller et. al. in 1983 [7]. In this necropsy evaluation of 40 elderly patients, the authors found that the grade of aortic valve calcium correlated with the severity of AS. Rubler et. al. extended these observations by using echocardiography to grade aortic valve calcium in 153 males with aortic valve disease [8]. The presence of moderate to severe aortic valve calcium identified those with severe AS confirmed by cardiac catheterization. The severity index was introduced by Bahler et. al. in 1999 as a new echocardiographic measure of aortic leaflet pathology and includes an assessment of both leaflet mobility and calcification [5]. In this study, the authors found that the severity index was independently associated with more rapid disease progression. However, their study included only patients with AS (aortic valve area $\leq 2.0 \mathrm{~cm}^{2}$ ). In our current study, we sought to validate this new echocardiographic scoring method against both invasive and noninvasive hemodynamic measures of aortic valve disease severity. Also, we included patients with aortic sclerosis, as well as patients with AS. The results show that, across the spectrum of calcific aortic valve disease, the severity index was correlated strongly with both the maximum aortic valve gradient, as measured by cardiac catheterization, and with the maximal transaortic jet velocity, as measured by echocardiography.

An important limitation of this study is that it is cross-sectional. Therefore, while it includes patients with lesser degrees of calcific aortic valve disease, it cannot determine whether the severity index provides useful prognostic 
Table I: Characteristics of entire study group.

\begin{tabular}{lc}
\hline Characteristic & $\mathbf{n = 4 8}$ \\
\hline Age (years, mean \pm SD*) & $56 \pm 9.7$ \\
Gender, M/F & $32 / 16$ \\
Hypertension, $\mathrm{n}(\%)$ & $32(67 \%)$ \\
Diabetes Mellitus, $\mathrm{n}(\%)$ & $17(35 \%)$ \\
Hyperlipidemia, $\mathrm{n}(\%)$ & $20(42 \%)$ \\
Smoking, $\mathrm{n}(\%)$ & $19(40 \%)$ \\
Family History of CAD, $\mathrm{n}(\%)$ & $16(33 \%)$ \\
Transaortic Jet Velocity by Echocardiography, (mean \pm SD*) & $2.2 \pm 1.3$ \\
Maximum Aortic Valve Gradient by Catheterization, (mean \pm SD*) & $26 \pm 30$ \\
Severity Index, (mean \pm SD*) & $5.0 \pm 2.5$ \\
AV Ca (I-6) (mean \pm SD*) & $3.3 \pm 1.7$ \\
AV Mobility (I-4) (mean $\pm S D *)$ & $1.8 \pm 0.94$ \\
\hline
\end{tabular}

$\mathrm{CAD}=$ coronary artery disease; $\mathrm{A} \vee \mathrm{Ca}=$ aortic valve calcium; $\mathrm{A} \bigvee$ Mobility = aortic valve mobility; $* \mathrm{SD}=$ Standard Deviation

i

Table 2: Characteristics of patients based on severity of aortic valve disease.

\begin{tabular}{|c|c|c|c|c|}
\hline Characteristic & Aortic Sclerosis n = 28 & Mild-Mod AS n = I 2 & Severe AS $\mathbf{n}=8$ & $P$ value \\
\hline Age (years, mean \pm SD*) & $56 \pm 8$ & $56 \pm 13$ & $59 \pm 10$ & 0.37 \\
\hline Gender Male/Female & $20 / 8$ & $8 / 4$ & $4 / 4$ & 0.54 \\
\hline Hypertension, n (\%) & 20 (7I\%) & $8(67 \%)$ & $4(50 \%)$ & 0.54 \\
\hline Diabetes Mellitus, n (\%) & $10(36 \%)$ & $5(42 \%)$ & $2(25 \%)$ & 0.74 \\
\hline Hyperlipidemia, n (\%) & $13(46 \%)$ & $4(33 \%)$ & $3(38 \%)$ & 0.72 \\
\hline Smoking, n (\%) & $12(43 \%)$ & $3(25 \%)$ & $4(50 \%)$ & 0.45 \\
\hline Family History of CAD, $n(\%)$ & II (39\%) & $4(33 \%)$ & I (13\%) & 0.32 \\
\hline $\begin{array}{l}\text { Maximum Aortic Valve Gradient by Catheterization } \\
\left(\mathrm{mean} \pm \mathrm{SD}^{*}\right)(\mathrm{mm} \mathrm{Hg})\end{array}$ & $7.0 \pm 2.8$ & $30 \pm 16$ & $83 \pm 24$ & $<0.0001$ \\
\hline $\begin{array}{l}\text { Transaortic Jet Velocity by Echocardiography, } \\
\left(\text { mean } \pm \mathrm{SD}^{*}\right)(\mathrm{m} / \mathrm{s})\end{array}$ & $1.29 \pm 0.27$ & $2.65 \pm 0.70$ & $4.54 \pm 0.60$ & $<0.0001$ \\
\hline Severity Index (0 to 12$)$ (mean $\left.\pm S D^{*}\right)$ & $3.38 \pm 1.06$ & $6.45 \pm 2.12$ & $8.38 \pm 1.41$ & $<0.0001$ \\
\hline $\mathrm{AV} \mathrm{Ca}(\mathrm{I}-6)\left(\right.$ mean $\left.\pm \mathrm{SD}^{*}\right)$ & $2.2 \pm 0.78$ & $4.1 \pm 1.6$ & $5.5 \pm 0.76$ & $<0.0001$ \\
\hline AV Mobility $(I-4)($ mean \pm SD*) & $1.2 \pm 0.43$ & $2.4 \pm 0.67$ & $3.3 \pm 0.49$ & $<0.0001$ \\
\hline
\end{tabular}

$\mathrm{CAD}=$ coronary artery disease $\mathrm{AV} \mathrm{Ca}=$ aortic valve calcium; $\mathrm{AV}$ Mobility = aortic valve mobility; $* \mathrm{SD}=$ Standard Deviation

nformation in these patients beyond that provided by more traditional hemodynamic measures. However, one retrospective study has reported that aortic valve thickening (a component of the severity index) is associated with increased risk of progression to AS [9]. Validation of the severity index as a prognostic marker for either future clinical events or progression to AS, could be examined in large, prospective studies that include serial echocardiograms.

\section{Conclusion}

In summary, these results confirm that the severity index correlates with hemodynamic severity of aortic valve disease and may prove to be a useful measure in the evaluation of patients with aortic sclerosis and AS.

\section{Abbreviations}

AS - Aortic Stenosis
D - Standard Deviation

CAD - Coronary Artery Disease

AV Ca - Aortic Valve Calcium

AV - Mobility Aortic Valve Mobility

\section{Competing interests}

The author(s) declare that they have no competing interests.

\section{Authors' contributions}

Author contributions include the following: (1) conception and design of study: KOB, DMS and MJB; (2) analysis and interpretation of data JT, NB, JR and (3) drafting of the manuscript: KOB, DMS, MJB or revising it critically for 
important intellectual content (all authors). All authors read and approved the final manuscript.

\section{Acknowledgements}

Robert M. Shavelle, PhD assistance provided statistical support.

\section{References}

I. Stewart BF, Siscovick D, Lind BK, Gardin JM, Gottdiener JS, Smith VE, Kitzman DW, Otto CM: Clinical factors associated with calcific aortic valve disease. Cardiovascular Health Study. J Am Coll Cardiol 1997, 29:630-634.

2. Otto CM, Burwash IG, Legget ME, Munt BI, Fujioka M, Healy NL, Kraft CD, Miyake-Hull CY, Schwaegler RG: Prospective study of asymptomatic valvular aortic stenosis. Clinical, echocardiographic, and exercise predictors of outcome. Circulation 1997, 95:2262-2270.

3. Palta S, Pai AM, Gill KS, Pai RG: New insights into the progression of aortic stenosis: implications for secondary prevention. Circulation 2000, I 0 I:2497-2502.

4. Rosenhek R, Binder T, Porenta G, Lang I, Christ G, Schemper M, Maurer $\mathrm{G}$, Baumgartner $\mathrm{H}$ : Predictors of outcome in severe, asymptomatic aortic stenosis. N Engl J Med 2000, 343:6 I I-6I7.

5. Bahler RC, Desser DR, Finkelhor RS, Brener SJ, Youssefi M: Factors leading to progression of valvular aortic stenosis. Am J Cardiol 1999, 84: 1044-1048.

6. Gorlin R, GORLIN SG: Hydraulic formula for calculation of the area of the stenotic mitral valve, other cardiac valves, and central circulatory shunts. I. Am Heart J I95I, 4 I: I-29.

7. Waller BF, Roberts WC: Cardiovascular disease in the very elderly. Analysis of $\mathbf{4 0}$ necropsy patients aged $\mathbf{9 0}$ years or over. Am J Cardiol I 983, 5 I:403-42 I.

8. Rubler S, King ML, Tarkoff DM, Dolgin M, Reitano J, Schreiber J: The role of aortic valve calcium in the detection of aortic stenosis: an echocardiographic study. Am Heart J 1985, I 09: 1049-1058.

9. Cosmi JE, Kort S, Tunick PA, Rosenzweig BP, Freedberg RS, Katz ES, Applebaum RM, Kronzon I: The risk of the development of aortic stenosis in patients with "benign" aortic valve thickening. Arch Intern Med 2002, 162:2345-2347.
Publish with Bio Med Central and every scientist can read your work free of charge

"BioMed Central will be the most significant development for disseminating the results of biomedical research in our lifetime. "

Sir Paul Nurse, Cancer Research UK

Your research papers will be:

- available free of charge to the entire biomedical community

- peer reviewed and published immediately upon acceptance

- cited in PubMed and archived on PubMed Central

- yours - you keep the copyright 